\title{
UJI PENURUNAN KANDUNGAN COD, BOD PADA LIMBAH CAIR PEWARNAAN BATIK MENGGUNAKAN Scirpus grossus DAN Iris pseudacorus DENGAN SISTEM PEMAPARAN INTERMITTENT
}

\author{
Bieby Voijant Tangahu, Dwi Agustiang Ningsih \\ Environmental Engineering Department, Civil Engineering and Planning Faculty, \\ Institut Teknologi Sepuluh Nopember (ITS) \\ Jl. Raya ITS, Surabaya 60111 Indonesia \\ e-mail: voijant@its.ac.id; dwiagustiang@gmail.com
}

\begin{abstract}
Mostly, batik industrial wastewater is produced from batik coloring process. One of this batik industry is located in Jetis, Sidoarjo since 1675. The wastewater produced from the coloring process in this location is directly dumped to Jetis river or drainage system around the area. One of the effective, efficient, and not costly wastewater treatment is by using phytotreatment process.

Plants used in this research are Scirpus grossus and Iris pseudacorus. Both of this plants can grow in polluted environment and suitable to be used in wastewater treatment process. Moreover, both of these plants are semi aquatic plant that can grow in both wet and dry condition. Intermittent exposure system can be applied to increase the efficiency of the phytotreatment process for batik industry wastewater. This system connects plant and wastewater periodically through flood and drain cycle $(F / D)$. This exposure can increase redox condition, so it can increase removal efficiency.

The study variables used in this research are species variation of plants Scirpus grossus and Iris pseudacorus (single plant or combined plant) and intermittent exposure system variation, which is F/D 2:1 and F/D 1:2. The Primary parameter of this research is the concentration reduction of BOD, COD, and color. The secondary parameter such as plant morphology, wet weight, and dry weight, $\mathrm{pH}$, and temperature.

Preliminary research that has been done for this research is plant acclimatization and range finding test to determine the wastewater concentration. Phytotreatment test is conducted for 18 days in intermittent phase. The result shows that the best variable to remove pollutant is combined plant reactor with intermittent exposure of $F / D$ 2:1 is able to remove $89 \%$ of COD and $97 \%$ of $B O D$.
\end{abstract}

Keywords: Batik coloring wastewater, BOD, COD, Phytotreatment, Intermittent, Iris pseudacorus, Scirpus grossus

\section{PENDAhUluan}

Produksi batik menjadi salah satu produksi yang potensial untuk dikembangkan. Data Kementerian Perindustrian menunjukkan kenaikan jumlah industri batik sejak 2011 hingga 2015 mencapai 14,7\%. Dalam proses produksinya, industri ini menghasilkan limbah cair yang jumlahnya mencapai $80 \%$ dari seluruh jumlah air yang dipergunakan dalam proses pembatikan (Watini, 2009). Kenaikan jumlah industri batik ini tidak disertai dengan sistem pengolahan limbah yang baik. Seperti halnya pada salah satu sentra industri batik di wilayah Jetis, Sidoarjo yang berdiri sejak tahun 1675. Berdasarkan Satrya (2015), produksi limbah dari industri batik di wilayah Jetis ini langsung dibuang ke Sungai Jetis atau drainase di sekitar rumah warga.

Menurut Suprihatin (2014), Industri batik merupakan salah satu penghasil limbah cair yang berasal dari proses pewarnaan atau pencelupan. Bahan-bahan kimia yang digunakan dalam proses pewarnaan antara 
lain zat warna asam, zat warna basa, zat warna direk, zat warna reaktif, zat warna naftol dan zat warna bejana (Kurniawan dkk., 2013). Penggunaan bahan kimia tersebut menyebabkan limbah batik memiliki kandungan warna, Biochemical Oxygen Demand (BOD), Chemical Oxygen Demand (COD), yang tinggi (Rashidi et al., 2012).

Upaya yang dilakukan untuk mengatasi dampak negatif pencemaran limbah cair industri batik adalah dengan melakukan pengolahan terlebih dahulu. Phytotreatment merupakan salah satu alternatif pengolahan limbah yang efektif, mudah diterapkan dan ekonomis (Tee et al., 2009).

Jenis tumbuhan yang akan digunakan pada penelitian ini adalah tumbuhan Scirpus grossus dan Iris pseudacorus. Menurut Stottmeister et al. (2003), Scirpus grossus dan Iris pseudacorus dapat hidup di lingkungan tercemar dan cocok dimanfaatkan untuk pengolahan limbah. Usaha dalam meningkatkan kinerja proses phytotreatment dalam mengolah air limbah batik dapat dilakukan dengan sistem pemaparan secara intermittent. Menurut Jia et al. (2010), sistem pemaparan secara intermittent mampu meningkatkan Dissolved Oxygen (DO) dalam media secara signifikan. Sistem pemaparan secara intermittent ini menghubungkan tumbuhan dengan larutan segar (limbah) secara berkala.

Berdasarkan hal tersebut, pengolahan limbah cair pewarnaan batik menggunakan tumbuhan Scirpus grossus dan Iris pseudacorus secara single plant ataupun combined plant dengan sistem pemaparan secara intermittent perlu diteliti. Hal ini dilakukan untuk mengetahui tingkat efisiensi penyisihan BOD, COD, dan warna yang dipengaruhi oleh variasi jenis tumbuhan melalui pemaparan secara intermittent.

\section{METODE PENELITIAN}

Penelitian dilakukan untuk memperbaiki kualitas buangan limbah cair pewarnaan batik menggunakan sistem phytotreatment dengan variasi jenis tumbuhan dan sistem pemaparan secara intermittent. Jenis tumbuhan yang digunakan dalam penelitian ini adalah Scirpus grossus dan Iris pseudacorus (Single plant dan Combined plant). Sistem pemaparan secara intermittent yang digunakan dengan perbandingan siklus flood and drain adalah F/D 1:2 dan F/D 2:1. Parameter utama yang digunakan adalah penurunan kadar BOD, COD. Pengamatan dilakukan dengan mengamati laju pertumbuhan Scirpus grossus dan Iris pseudacorus yang terpapar limbah dengan waktu dan konsentrasi tertentu. Berikut merupakan penjelasan dari tahapan penelitian: 


\section{a. Tahap propagasi}

Propagasi dilakukan untuk memperbanyak bibit tumbuhan yang diperlukan untuk penelitian. Berdasarkan Al-Baldawi et al. (2015), selama masa propagasi akan dilakukan pengamatan terhadap laju pertumbuhan tumbuhan (growth rate) dan dibiarkan sampai tumbuh tunas (second generation). Tumbuhan dengan umur dan tinggi yang sama akan digunakan pada setiap tahapan penelitian, diharapkan dengan demikian kondisi awal tumbuhan yang digunakan adalah sama.

b. Aklimatisasi

Aklimatisasi tumbuhan dilakukan supaya tumbuhan Scirpus grossus dan Iris pseudacorus L dapat menyesuaikan diri dengan kondisi dan media yang akan digunakan pada tahap uji RFT dan uji phytotreatment. Tahap ini dilakukan selama 7 hari menggunakan media kerikil tanpa pencemar, dan menggunakan air PDAM. Aklimatisasi tumbuhan dilakukan dalam reaktor box plastik berukuran $35 \mathrm{~L}$. Pada kondisi ini diharapkan tumbuhan dapat beradaptasi dengan karakteristik tumbuh subur (tidak layu dan mati). Tumbuhan dengan kondisi inilah yang akan digunakan untuk tahap RFT dan penelitian utama.

\section{c. RFT (Range Finding Test)}

RFT dilakukan untuk mengetahui seberapa besar kemampuan tumbuhan dalam menyerap polutan pada konsentrasi tertentu. Tahap ini dilakukan dengan membuat variasi konsentrasi air limbah yang kemudian akan diujikan pada tumbuhan pengolah. Variasi konsentrasi yang akan digunakan adalah 0\% (kontrol), $10 \%, 20 \%, 30 \%, 40 \%$, dan $50 \%$.

\section{d. Uji phytotreatment}

Penelitian dilakukan dengan menyiram setiap reaktor yang sudah berisi media kerikil dengan limbah cair pewarnaan batik. Variasi sistem pemaparan secara intermittent dilakukan dengan perbandingan siklus flooding dan drying (F/D). Pemaparan secara intermittent yaitu reaktor diberi air limbah (flooding) secara intermittent dengan ada jeda waktu dimana reaktor dibiarkan kering tidak diberi air limbah (drying). Flooding dengan memasukkan air ke dalam reaktor dalam kondisi lubang outlet ditutup. Keadaan flooding dilakukan dengan reaktor diberi air limbah, kemudian air ditahan dalam reaktor selama variasi periode flooding (1 atau 2 hari). Drying dengan membuka lubang outlet dan tidak ada air yang dimasukkan ke reaktor. Keadaan drying dilakukan dengan mengeluarkan air dalam reaktor melalui outlet. 


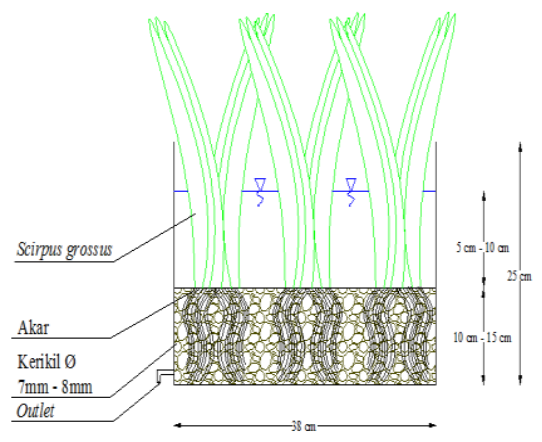

(a)

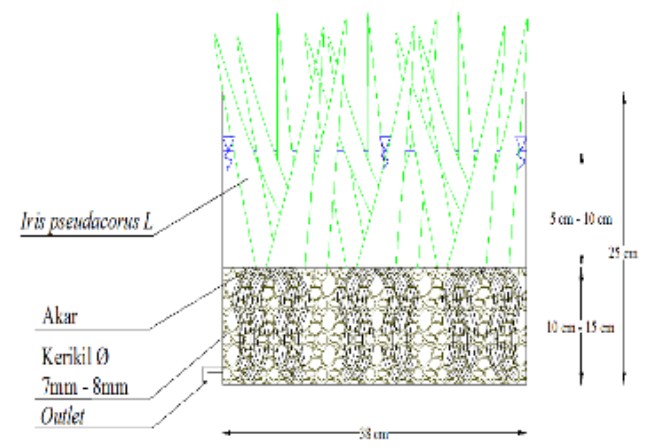

(b)

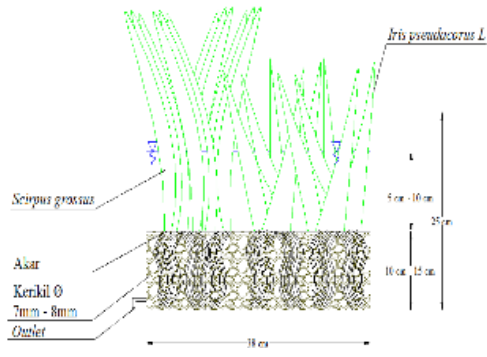

(c)

Gambar 1 Reaktor Penelitian (a) Reaktor Single Plant (Scirpus grossus), (b) Reaktor Single Plant (Iris pseudacorus ), (c) Reaktor Combined Plant (Scirpus grossus dan Iris pseudacorus)

\section{HASIL DAN PEMBAHASAN}

\section{a) Uji karakteristik Limbah Batik}

Limbah yang akan digunakan adalah limbah pewarna merah pada proses pembatikan. Limbah diambil dari di salah sentra batik Jetik, Sidoarjo. Hasil uji karakteristik limbah batik dapat dilihat pada Tabel 1

Tabel 1. Hasil Uji Karakteristik Limbah Pewarna Batik Jetis

\begin{tabular}{lllll}
\hline No & Parameter & \multicolumn{1}{c}{ Satuan } & $\begin{array}{c}\text { Hasil } \\
\text { Analisa }\end{array}$ & $\begin{array}{c}\text { *Baku } \\
\text { Mutu }\end{array}$ \\
\hline 1 & $\mathrm{pH}$ & - & 10,80 & $6-9$ \\
2 & $\mathrm{TSS}$ & $\mathrm{mg} / \mathrm{L}$ & 1180 & 50 \\
3 & $\mathrm{COD}$ & $\mathrm{mg} / \mathrm{L} \mathrm{O}_{2}$ & 3855 & 150 \\
4 & $\mathrm{BOD}$ & $\mathrm{mg} / \mathrm{L} \mathrm{O}_{2}$ & 2710 & 60 \\
5 & Sulfida & $\mathrm{mg} / \mathrm{L} \mathrm{H}_{2} \mathrm{~S}$ & 0,00 & 0,3 \\
6 & Ammonia & $\mathrm{mg} / \mathrm{L} \mathrm{NH}_{2}-\mathrm{N}$ & 180,92 & 8 \\
& total & & & \\
7 & $\begin{array}{l}\text { Total } \\
\text { kromium }\end{array}$ & $\mathrm{mg} / \mathrm{L} \mathrm{Cr}$ & 0,45 & 1 \\
8 & $\begin{array}{l}\text { Minyak } \\
\text { dan lemak }\end{array}$ & $\mathrm{mg} / \mathrm{L}$ & 70 & 3 \\
9 & phenol & $\mathrm{mg} / \mathrm{L}$ & 0 & 0,5 \\
\hline
\end{tabular}

* Kep. Gubernur Jawa Timur no. 72/2013 
Berdasarkan hasil analisis parameter awal, didapatkan bahwa nilai BOD dan COD limbah pewarna industri batik Jetis sebesar $2710 \mathrm{mg} / \mathrm{L}$ dan $3855 \mathrm{mg} / \mathrm{L}$. Nilai ini melebihi dari baku mutu limbah tekstil berdasarkan Peraturan Gubernur Jawa Timur no. 72 tahun 2013.

\section{b) Range Finding Test (RFT)}

Range finding test (RFT) digunakan untuk mengetahui seberapa besar kemampuan tumbuhan dalam menyerap polutan pada konsentrasi tertentu. Tumbuhan yang digunakan dalam RFT adalah tumbuhan hasil aklimatisasi sebelumnya. Hal ini dilakukan supaya tumbuhan sudah beradaptasi dengan lingkungan pada lokasi penelitian.

Dari hasil pengamatan selama 7 hari, terlihat bahwa tumbuhan Scirpus grossus mampu hidup dengan baik pada konsentrasi limbah sebesar 20\% yang setara dengan 770,92 mg/L COD dan 542 mg/L BOD. Pada konsentrasi 30\% sampai 50\% Scirpus grossus tidak dapat hidup dengan baik, ditandai dengan daun yang layu dan menguning. Tumbuhan Iris pseudacorus dapat tumbuh dengan baik pada konsentrasi limbah 30\% yang setara dengan 1156,4 mg/L COD dan $813 \mathrm{mg} / \mathrm{L}$ BOD. Tumbuhan ini mengalami kematian, layu, dan daun menguning pada konsentrasi 40\% sampai 50\%. Pengamatan secara fisik pada tumbuhan dapat dilihat pada Gambar 1 dan Gambar 2.

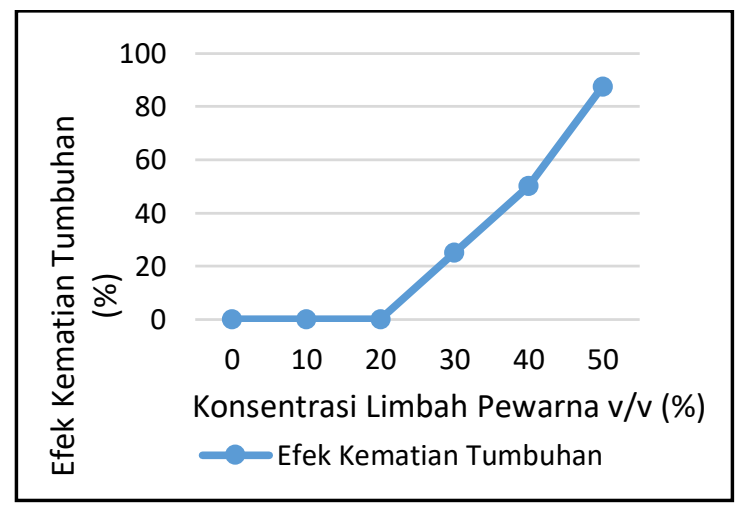

Gambar 2 Lengkung Dosis Limbah Pewarnaan hasil RFT Scirpus grossus 


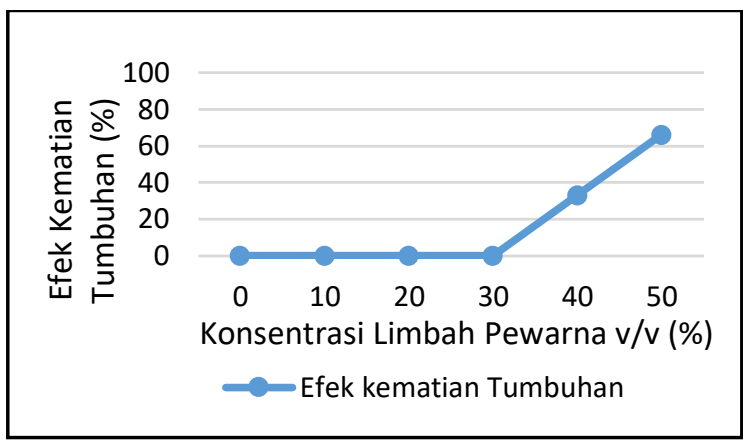

Gambar 3 Lengkung Dosis Limbah Pewarnaan Hasil RFT Iris pseudacorus

\section{c) Uji Phytotreatment}

Penelitian utama yaitu tahap uji phytotreatment ini adalah dengan sistem pemaparan secara intermittent. Tumbuhan yang digunakan adalah tumbuhan yang sudah melalui tahap aklimatisasi sebelumnya, supaya tumbuhan sudah beradaptasi dengan kondisi yang akan digunakan dalam uji pytotreatment. Konsentrasi limbah yang digunakan adalah konsentrasi limbah hasil RFT yang tidak menimbulkan efek kematian pada tumbuhan. Variasi sistem yang akan digunakan yaitu F/D 1:2 (masa flooding selama 1 hari, dan drying selama 2 hari), dan F/D 2:1 (masa flooding selama 2 hari, dan drying selama 1 hari), yang dilakukan selama 18 hari. Adapun variasi tumbuhan yang digunakan yaitu Jenis tumbuhan yang digunakan adalah Scirpus grossus dan Iris pseudacorus yang dilakukan dalam kondisi single plant (Scirpus grossus atau Iris pseudacorus) dan kondisi combined plant (Scirpus grossus dan Iris pseudacorus) dengan ratio jumlah tumbuhan 50:50. Hasil analisa removal BOD dan COD dapat dilihat pada Gambar 4 sampai Gambar 7.

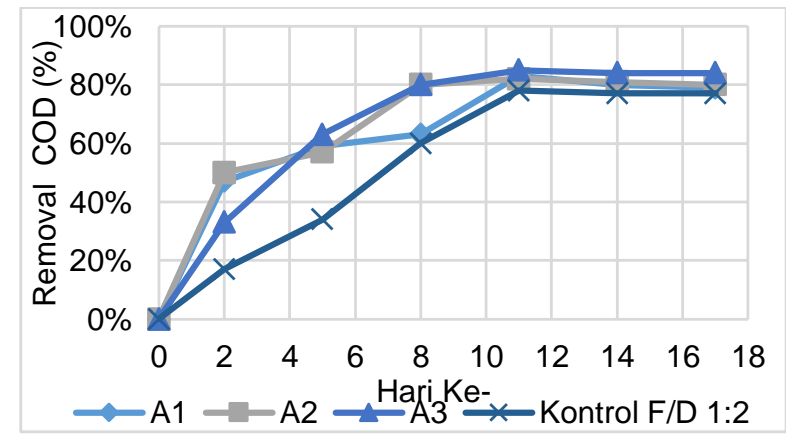

Gambar 4 Penurunan COD limbah pewarnaan pada F/D 1:2 


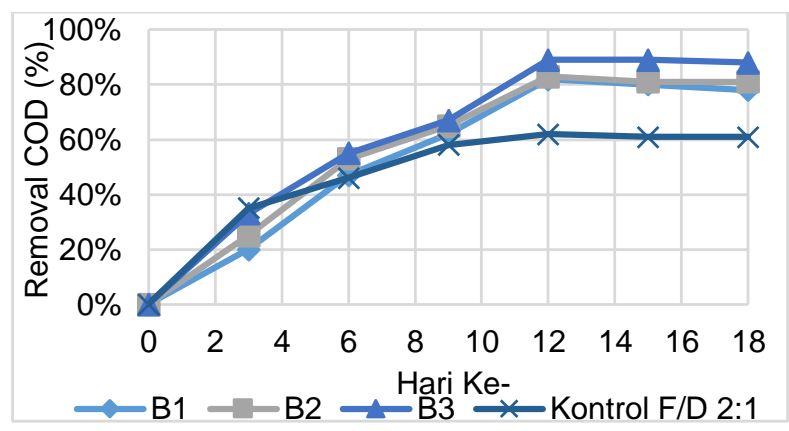

Gambar 5 Penurunan COD limbah pewarnaan pada F/D 2:1

Pada reaktor F/D 1:2 dan F/D 2:1 efisiensi removal pada masing-masing variasi single plant maupun combined plant cenderung lebih meningkat dan lebih besar dari pada kontrol di hari pengamatan ke- 0 sampai ke-14. Penyisihan paling besar pada air limbah pewarnaan terjadi pada hari ke- 11 untuk reaktor F/D 1:2 dan hari ke-12 untuk reaktor F/D 2:1 (masing-masing pada feeding limbah ke 4). Pada reaktor single plant Scirpus grossus menunjukkan nilai removal 83\% pada pemaparan F/D 1:2, 82\% pada pemaparan F/D 2:1. Pada reaktor single plant Iris pseudacorus menunjukkan nilai removal $82 \%$ pada pemaparan F/D 1:2, $83 \%$ pada pemaparan F/D 2:1. Pada reaktor combined plant menunjukkan nilai removal 85\% pada pemaparan F/D 1:2, 89\% pada pemaparan 2:1. Reaktor kontrol menunjukkan efisiensi removal sebesar 78\% pada raktor F/D 1:2 dan 60\% pada reaktor F/D 2:1. Nilai removal tertinggi dimiliki oleh reaktor combined plant. Hal ini disebabkan karena terjadinya kompetisi antar spesies tumbuhan dalam memperebutkan nutrisi dalam reaktor pytotreatment, sehingga menyebabkan konsentrasi COD dalam raktor tersebut mengalami penurunan. Proses pengolahan air limbah yang terjadi pada reaktor uji pytotreatment adalah filtrasi, absorbsi oleh mikroorganisme dan adsorpsi bahan organik oleh akar-akar tumbuhan (Novotny dan Olem, 1994). Kenaikan nilai removal COD semakin hari semakin meningkat. Hal ini terjadi karena proses degradasi akan mulai efektif ketika mikroorganisme di dalam zona akar sudah mulai tumbuh dalam jumlah yang banyak. Prinsip kerja sistem yang dilakukan adalah dengan memanfaatkan simbiosis antara tumbuhan dengan mikroorganisme dalam media di sekitar sistem perakaran (Rhizosphere) tumbuhan tersebut.

Kenaikan nilai removal tertinggi dimiliki oleh reaktor dengan sistem pemaparan intermittent F/D 2:1. Penerapan siklus flooding selama 2 hari memberikan waktu kontak limbah terhadap sistem pengolahan lebih lama dari pada penerapa siklus flooding 1 hari. Penurunan parameter limbah sangat bergantung pada aktivitas organisme dan kemampuan tumbuhan dalam menyerap unsur hara, oleh karena itu 
semakin lama waktu pemaparan maka semakin besar materi organik yang tereliminasi melalui mekanisme biodegradasi (Dhamayanthie, 2000).

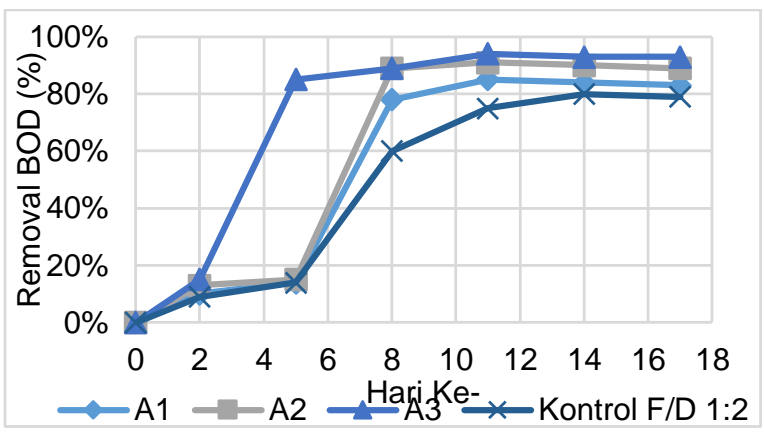

Gambar 6 Penurunan BOD limbah pewarnaan pada F/D 1:2

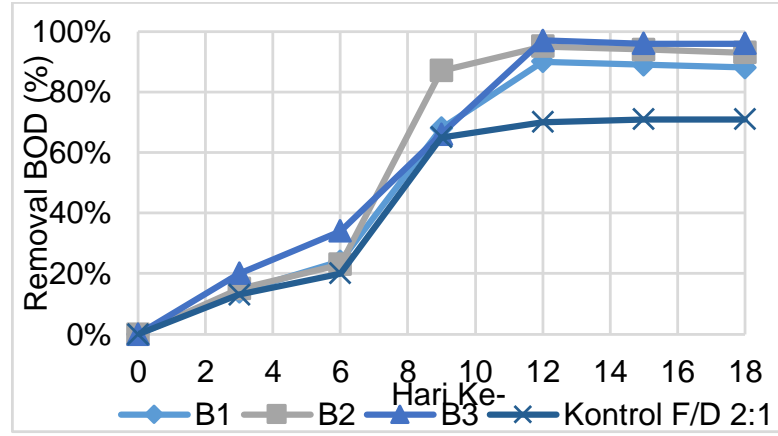

Gambar 7 Penurunan BOD limbah pewarnaan pada F/D 2:1

Pada reaktor F/D 1:2 efisiensi removal pada masing-masing variasi single plant maupun combined plant cenderung lebih meningkat dan lebih besar dari pada kontrol di hari pengamatan ke- 0 sampai ke-14. Penyisihan paling besar pada air limbah pewarnaan terjadi pada hari ke- 11 untuk reaktor F/D 1:2 dan hari ke-12 untuk reaktor F/D 2:1 (masing-masing pada feeding limbah ke 4). Pada reaktor single plant Scirpus grossus menunjukkan nilai removal 85\% pada pemaparan F/D 1:2, 90\% pada pemaparan F/D 2:1. Pada reaktor single plant Iris pseudacorus menunjukkan nilai removal $91 \%$ pada pemaparan F/D 1:2, 95\% pada pemaparan F/D 2:1. Pada reaktor combined plant menunjukkan nilai removal 94\% pada pemaparan F/D 1:2, 97\% pada pemaparan 2:1. Reaktor kontrol menunjukkan efisiensi removal sebesar $75 \%$ pada raktor F/D 1:2 dan 70\% pada reaktor F/D 2:1. Nilai removal tertinggi dimiliki oleh reaktor combined plant F/D 2:1. Kenaikan nilai removal combined plant dimulai dari pengamatan hari ke- 4. Hal ini disebabkan karena terjadinya kompetisi antar spesies tumbuhan dalam memperebutkan nutrisi dalam 
reaktor pytotreatment, sehingga menyebabkan konsentrasi BOD dalam raktor tersebut mengalami penurunan.

Senyawa organik yang terkandung di dalam limbah pewarnaan menjadi sumber nutrisi bagi mikroba yang selanjutnya diubah menjadi senyawa yang lebih sederhana. Melalui pytotreatment, proses penurunan pencemar dalam limbah menggunakan tumbuhan merupakan kerjasama antara tumbuhan dan mikroba yang berada pada tumbuhan tersebut (Hayati, 1992). Jumlah bahan organik yang dirombak oleh mikroorganisme berbanding lurus dengan pertumbuhan mikroorganisme pengurai. Semakin lama waktu pemaparan maka proses perombakan bahan organik oleh mikroorganisme dapat dilakukan secara sempurna. Melalui proses filtrasi, penguraian dan penyerapan, bahan-bahan organik sebagian akan mengalami bentuk yang lebih sederhana sementara yang lain akan diserap oleh tumbuhan. Kenaikan nilai removal tertinggi dimiliki oleh reaktor dengan sistem pemaparan intermittent F/D 2:1. Selain pengaruh lamanya kontak limbah dan peran tumbuhan maupun media, sistem pamaparan intermittent dengan penerapan siklus flood and drain juga berpengaruh. Kemampuan tumbuhan dalam menyerap bahan organik semakin lama akan semakin meningkat karena melalui siklus drying memberikan kesempatan kepada tumbuhan untuk bisa memulihkan kemampuannya dalam menyerap kontaminan.

\section{KESIMPULAN}

Kesimpulan yang dapat diambil dari penelitian ini adalah:

a. Konsentrasi BOD dan COD tertinggi yang mampu disisihkan adalah sebagai berikut: Reaktor combined plant dengan sistem pemaparan intermittent F/D 2:1 mampu menyisihkan COD sebesar 89\%, BOD sebesar 97\%. Tumbuhan Scirpus grossus dan Iris pseudacorus mampu menyisihkan COD sebesar 29\%, BOD sebesar $27 \%$.

b. Sistem pamaparan intermittent yang paling efektif pada penyisihan BOD, COD dan warna limbah batik adalah F/D 2:1 (2 hari terpapar limbah dan 1 hari tidak terpapar limbah).

\section{DAFTAR PUSTAKA}

Dhamayanthie, I., (2000), Pengolahan Limbah Cair Industri Textile dengan Proses Anaerob, Thesis Master, Program Studi Teknik Kimia, Program Proses Sarjana ITB Bandung.

Hayati, N. (1992). Kemampuan eceng gondok dalam mengubah sifat fisik kimia limbah cair pabrik pupuk urea dan asam formiat. Bandung: Pasca sarjana biologi Institut Teknologi Bandung. 
Kurniawan, M.W., Purwanto,P., dan Sudarso,S. (2013). Stratergi Pengelolaan Air Limbah Sentra UMKM Batik yang Berkelanjutan di Kabupaten Sukoharjo . Jurnal Ilmu Lingkungan, 11(2), hal. 62-72.

Novoty, V. dan Olem, H. (1993). Water Quality: Prevention, Identification and Management of Difuse Pollution. Van Nostrand Reinhold: New York.

Rashidi, H.R., Sulaiman, N.N.M., Hashim, N.A. (2012). Batik Industry Synthetic Wastewater Treatment using.

Satrya, R.W. (2015). Sejarah Industrialisasi Batik Di Kampung Batik Jetis Sidoarjo Tahun 19702013. E-Journal Pendidikan Sejarah, 3(3), hal. 480-486.

Stottmeister U., A. WieBner, P. Kuschk, U. Kappelmeyer, M. Kastner, 0. Bederski, R. A. Miiller, dan H. Moormann. (2003). Effects of Plants and Microorganisms In Constructed Wetlands For Wastewater Treatment. Biotech. Advances, 22, hal. 93-117.

Suprihatin, H. (2014). Kandungan Organik Limbah Cair Industri Batik Jetis Sidoarjo Dan Alternatif Pengolahannya. Tugas Akhir untuk Memperoleh Gelar Sarjana Teknik Lingkungan, Institut Teknologi Pembangunan, Surabaya.

Tee, H.C., Seng, C.E., dan Lim Noor, A. Md, P.E. (2009). Performance comparison of constructed wetlands with gravel-and rice husk-based media for phenol and nitrogen removal. Sci. Total Environ, 407, hal. 3563-3571.

Watini. (2009). Pengaruh Waktu Kontak Eceng Gondok (Eichornia crassipes) terhadap Penurunan Kadar Cd dan Cr Pada Air Limbah Industri Batik (Home Industry Batik Di Desa Sokaraja Lor). Tugas Akhir untuk Memperoleh Gelar Sarjana Ilmu Kesehatan, UNSOED, Purwokerto. 